\title{
Uzy Bory, un symbole de la culture oudmourte contemporaine
}

Sébastien Cagnoli

\section{OpenEdition}

1 Journals

Édition électronique

URL : https://journals.openedition.org/efo/4300

DOI : $10.4000 /$ efo. 4300

ISSN : 2275-1947

Éditeur

INALCO

Édition imprimée

Date de publication : 1 janvier 2014

ISBN : 978-2-343-05394-3

ISSN : 0071-2051

\section{Référence électronique}

Sébastien Cagnoli, «Uzy Bory, un symbole de la culture oudmourte contemporaine », Études finnoougriennes [En ligne], 46 | 2014, mis en ligne le 15 octobre 2015, consulté le 08 juillet 2021. URL: http://journals.openedition.org/efo/4300 ; DOI : https://doi.org/10.4000/efo.4300

Ce document a été généré automatiquement le 8 juillet 2021.

\section{c.) (i) (8)}

Études finno-ougriennes est mis à disposition selon les termes de la Licence Creative Commons Attribution - Pas d'Utilisation Commerciale 4.0 International. 


\title{
Uzy Bory, un symbole de la culture oudmourte contemporaine
}

\author{
Sébastien Cagnoli
}

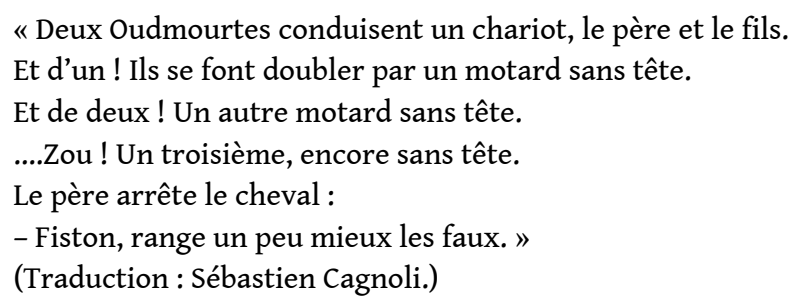

C'est à travers cette parabole humoristique que nous entrons dans le film bucolique de Piotr Pałgan et Darali Leli, présenté pour la première fois à Iževsk en Oudmourtie le 7 mars 2011. Cette comédie romantique à l'intrigue simple fleure bon la campagne oudmourte et montre les Oudmourtes citadins sous un angle volontairement caricatural. Uzy Bory ${ }^{1}$, «Les Fraises » en français, est un long métrage frais et dépaysant, d'un genre nouveau dans le panorama de la culture oudmourte et qui réchauffe le cœur. Après avoir été présenté dans les cinémas de la République, le film a été télédiffusé à une heure de grande écoute et a réuni plus de 30000 spectateurs. Cette notoriété est l'un des éléments qui permettent de considérer la sortie d'Uzy Bory comme un évènement culturel symbolique d'une jeune génération d'Oudmourtes résolus à engager leur culture dans le $\mathrm{XxI}^{\mathrm{e}}$ siècle en tenant compte des critères de l'époque : le produit culturel doit pouvoir être compétitif. Les caractéristiques de ce long métrage (comédie romantique, personnages esquissés, esthétique soignée, diffusion télévisuelle facile d'accès) lui permettent de concurrencer les produits culturels de masse, russes ou américains, qui inondent le marché et noient les manifestations culturelles plus confidentielles.

\section{Genèse du film et synopsis}

2 Uzy Bory est issu de l'histoire d'amour entre un traducteur polonais, Piotr Pałgan, et la culture oudmourte, qu'il découvre à Budapest par l'intermédiaire d'amis oudmourtes. 
Avec un parcours de polyglotte admirateur du poète polonais Słonimski ${ }^{2}$, il est presque normal que ce soit Piotr Pałgan qui ait réussi le pari de regrouper un nombre suffisant de volontaires enthousiastes pour porter encore plus en avant la culture oudmourte.

Il cite d'ailleurs un poème d'A. Słonimski en réponse à ma question sur la genèse du film :

Celui-là est de ma patrie

Celui-là qui oublie son propre pays

En apprenant que coule le sang du peuple tchèque,

Qui se sent frère des Yougoslaves,

Norvégien quand souffre le peuple norvégien,

Se penche avec la mère juive sur ses fils battus,

Se tordant les mains de douleur,

Quand le Moscale tombe - se sent Moscale,

Pleure l'Ukraine avec les Ukrainiens,

Celui-là qui ouvre son cœur à tous,

Qui est français quand la France souffre - Grec

Quand le peuple grec meurt de faim,

Celui-là est de ma patrie. Il est homme.

Antoni Słonimski, 1943

4 C'est à l'université, où le producteur enseigne actuellement la langue polonaise, qu'il a recruté certains des acteurs qui réjouissent par leur jeunesse et leur beauté. Le scénario et les dialogues du film sont un véritable bijou que nous devons à l'artiste Darali Leli qui est aussi la réalisatrice d'Uzy Bory. Les prises de vues, toujours belles, ainsi que les aspects techniques, sont le fruit du travail de Dominique Pałgan (le frère de Piotr) et de ses amis polonais ${ }^{3}$.

Uzy Bory raconte l'histoire de Maksim (Konstantin Nikitin), jeune Oudmourte du village de Gondygurt (le village de l'ours), amoureux d'une chanteuse à succès d'Iževsk (Lena Frolova). La famille et les amis de Maksim mettront tout en œuvre pour l'aider à conquérir Viktoria. C'est « l'opération Finlande », du nom d'un pays qui est - paraît-il très accueillant pour les Oudmourtes, surtout au moment de la cueillette des fraises: les jeunes hommes du village font une plaisanterie grivoise en conférant un double sens au mot « fraise », utilisé aussi comme métaphore de la femme ; de surcroît, «Viktoria » est aussi le nom d'une variété de fraise.

\section{Oudmourtes des villes, Oudmourtes des champs}

6 Les personnages sont des stéréotypes inspirés d'amis oudmourtes de Piotr Pałgan. On ne peut s'empêcher de sourire, d'ailleurs, en retrouvant la mère oudmourte de Maksim et Dydy, qui rappelle inévitablement de bons souvenirs à ceux qui se sont promenés dans les villages oudmourtes.

Le héros, sa famille et ses amis sont des Oudmourtes de la campagne qui vivent de façon traditionnelle : mode de vie rural et économie agraire, cuisine oudmourte, cohésion familiale (le petit fils écoute les conseils du grand-père), cohésion sociale (réunions de buskel, la communauté villageoise oudmourte, où l'on chante), goût pour les métaphores et plaisir de la langue. Nous pouvons à ce sujet citer le très beau passage où Dydy, la sœur de Maksim, accueille son fiancé au village. Il rentre de l'armée et raconte 
ses malheurs en mêlant des mots russes à l'oudmourte (les termes en russe sont en italique) :

\begin{tabular}{|c|c|}
\hline д- Алло. & D - Allo. \\
\hline м- дыды? & M - Dydy? \\
\hline Д- МИТРЕЙ? & D - Mitrej ? \\
\hline М- МОН БЕРТӤ! & M - Je suis de retour! \\
\hline Д- КЫТЫСЬ БЕРТӤД? & D - D'où? \\
\hline м- кызьы кытысь? АРмиысь! & M - Comment d'où ? Mais de l'armée! \\
\hline д- АРмиысь?! тон кытын Али? & D - De l'armée ?! Tu es où, là ? \\
\hline М - УКНО УЛАД. & $M$ - Sous ta fenêtre. \\
\hline д- УКно УЛАм?! & D - Sous ma fenêtre ?! \\
\hline М - БЕН. & M - Oui. (Dydy rejoint Mitrej) \\
\hline Д- МИТРЕЙ! & D - Mitrej! \\
\hline М - ДЫДЫ! КАЛЛЕНГЕС, КАЛЛЕНГЕС! & M - Dydy! Attention, attention! \\
\hline Д- МАИН ВУИД? & D - Comment es-tu rentré ? \\
\hline М - АВТОБУСЭН. КЕЧОЛЫН ВАСЬКИ. & M - En bus. Je suis descendu à Ketchevo. \\
\hline д - ПЫДЫН-А МАР-А? & D - Et puis à pied? \\
\hline м - ЧИДАНЭ ӦЗ ТЫРМЫ. & M - J'en avais marre. \\
\hline $\begin{array}{l}\text { Д- МИТя! ГУДЫРИКОШКОН ГИНЭ УК АЙ АЛИ... ТОН } \\
\text { сйЗьЫЛ БЕРТЫНЫ КУЛЭ ВАЛ. }\end{array}$ & $\begin{array}{l}\text { D - Mitja! Mais on n'est qu'en août... Tu devais } \\
\text { rentrer en automne. }\end{array}$ \\
\hline М - НУ МАРЫН... ВИСЁНЭН ЙЫРИН. & M - C'est à cause de la santé. \\
\hline Д- ТОН ШУЗИГЕС-А МАР-А? & D - Un problème à la tête? \\
\hline м - ӧвӧл. пыды. & M - Non non. Au pied. \\
\hline д- пыдыд?! & D - Au pied? \\
\hline М - КӦНЯ КЕ ХРОМАЮ. & M - Je claudique un peu. \\
\hline Д- «ХРОМАЮ»... ЧУТИСьКОД ШУ! & D - Dis plutôt que tu « boites »! \\
\hline $\begin{array}{l}\text { М - ПАЛУБАЕЗ, МИСЬКЫКУМ ПОСКОЛЬЗНУЛСЯ НО } \\
\text { ТӤНИ, ЧИНЬЫМЕ ЧИГТӤ. }\end{array}$ & $\begin{array}{l}\text { M - J'ai fait une chute en lavant le pont et je } \\
\text { me suis cassé un orteil. }\end{array}$ \\
\hline $\begin{array}{l}\text { Д- ЭЭ, МИСКИНЬ! ОГШОРЫ ГЫЛӞЫСА УСьЫСАЛЫД } \\
\text { КЕ, ӦД НО ЧИГТЫСАЛЫД, ДЫР... «ПОСКОЛЬЗНУЛСЯ» } \\
\text { ШУ.» }\end{array}$ & $\begin{array}{l}\text { D - Oh mon pauvre! Si tu étais tombé peut- } \\
\text { être qu'il ne serait pas cassé ! Mais tu as «fait } \\
\text { une chute».» }\end{array}$ \\
\hline
\end{tabular}

8 Ce passage est aussi une allusion à la fonction assimilatrice du service militaire qui dure douze mois en Russie. Ce passage obligé est reconnu comme étant extrêmement violent. Les bizutages brutaux (qui vont jusqu'au viol et à la torture) y sont institutionnalisés, les suicides n'y sont pas rares. Les mères savent et disent que leurs fils vont revenir traumatisés et, dans certains cas, alcooliques et dépressifs. Les 
organisations nationales, comme l'Union des comités des mères de soldats ${ }^{4}$, et internationales (Amnesty International, entre autres) font un constat édifiant de la situation. Les Oudmourtes n'y échappent évidemment pas et, même si cette situation n'est pas le sujet principal du film, les références à l'assimilation culturelle (par la langue) et à la souffrance physique endurée sont manifestes.

Deux personnages représentent les Oudmourtes citadins : Vika et Robert, son manager. En plus, l'opposant à l'histoire d'amour, Almaz, l'infidèle fiancé tatare, vit aussi en ville.

La chanteuse oudmourte est conditionnée par le mode de vie de la ville et le statut de célébrité qui est le sien. Elle est pourtant sensible à la langue oudmourte (elle refuse de parler russe avec un jeune homme qui l'aborde) et sera finalement conquise par la pureté de l'amour de Maksim. Néanmoins, on ne sait pas où vivront ces deux-là car la scène finale se déroule sur un bateau (probablement sur le lac artificiel d'Iževsk), dans un milieu qui n'est pas exactement la ville, ni exactement la campagne. En somme, la question de la réunion entre la tradition oudmourte et la vie citadine n'est pas résolue dans le film. C'est seulement dans un ailleurs liquide (le lac) et mobile (le bateau) que Maksim et Vika peuvent se retrouver. Mais comment, de toute façon, répondre à cette question qui représente un enjeu majeur pour l'avenir de la culture oudmourte?

Robert est un personnage drôle et sympathique qui pique la curiosité. Dandy noctambule, il dirige la carrière de Vika qui se produit dans les boîtes de nuit d'Iževsk. La vodka aidant, il se laissera pourtant convaincre par le grand-père de Maksim d'amener Vika à Gondygurt pour qu'elle y donne un concert. Avec ses égarements, ses comportements outrés, son mode de vie nocturne et ses accoutrements voyants, Robert est représentatif d'une culture urbaine radicalement en rupture avec la tradition oudmourte. C'est un homosexuel oudmourte citadin. Le pari des auteurs du film était risqué : ce personnage n'allait-il pas susciter un sentiment négatif parmi le public? Il semblerait qu'au contraire, ce soit la figure favorite des spectateurs, et pour cause, c'est un prototype d'oudmourte idéal : il est et parle oudmourte bien qu'originaire de la ville, il manifeste une position sociale décomplexée et exerce un métier valorisé. De plus, le statut du personnage de Robert évolue au fur et à mesure de la narration; certes, il incarne la ville et son influence négative, qui éloigne de la nature, mais une fois débarrassé de son vernis clinquant de citadin il s'acclimate fort bien à la campagne et à ses habitants. Robert est un rêve oudmourte : il passe de la ville à la campagne avec la même aisance ; grâce à sa candeur, sa générosité et son humour, il est aimé de tous.

Le schéma actanciel est simple: un héros en quête de sa bien-aimée est aidé par les adjuvants, les personnages issus de la campagne (à l'exception de Robert dont le statut change) ; les opposants sont le fiancé tatare et la ville, le monde de la nuit dans le film. Cette simplicité participe à l'effet naïf et romantique que produit le film.

\section{Uzy Bory : Un pied de nez à l'oppression culturelle.}

13 À la question

qu'avez-vous fait, et voulu faire avec ce film?,

Piotr Pałgan a répondu vouloir

influencer le subconscient des Oudmourtes et montrer qu'ils ne sont pas moins bien que les Russes. Eux aussi sont beaux et jeunes, ils peuvent avoir des histoires d'amour complexes, avec des rebondissements, et faire des blagues. Il était triste, auparavant, de parler d'amour en Oudmourtie. ${ }^{5}$ 
Uzy Bory est un paradoxe. L'auteur utilise les codes de l'uniformisation culturelle (les médias cinématographique et télévisuel, le genre de la comédie romantique, la beauté et la jeunesse des acteurs) pour échapper à l'oppression culturelle russe. Dans la même logique, c'est à travers des thèmes universels comme la quête amoureuse, les doutes et les émois de l'adolescence, que sont abordés les problèmes spécifiques rencontrés par les Oudmourtes de la campagne et de la ville (discrimination, difficultés sociales et économiques).

Depuis la fin de la période soviétique, on a vu se dessiner une offre culturelle oudmourte de deux types: une culture officielle folklorisée et une culture originale confidentielle. La première est typiquement représentée par les ensembles folkloriques comme Ajkaj ou Italmas qui se produisent sur scène et constituent la vitrine de la culture oudmourte. Ces produits culturels ont du succès auprès des Oudmourtes assimilés ou non, et séduisent aussi les amateurs d'exotisme du monde entier. Le Ministère de la Politique nationale, dont la mission principale est d'éviter les conflits entre les minorités nationales, a notamment en charge les programmes officiels de préservation de la langue et de la culture oudmourtes. Le premier programme (2005-2009) s'adressait à tous les locuteurs de l'oudmourte et avait pour objectif de favoriser le bilinguisme par la publication d'ouvrages dans tous les genres, de journaux de presse locale et nationale, ainsi que la création d'émissions télévisées et radiophoniques en oudmourte. Ce projet ne semble pas avoir donné les résultats escomptés. En effet, même si les résultats de l'application de ce programme n'ont pas été mis à la disposition du public, une enquête à mi parcours à été effectuée par le Ministère: entre 2005 et 2007 seuls dix-neuf titres ont été publiés en langue oudmourte, pour un total de 50.000 exemplaires. Il existe une presse en oudmourte, mais il est difficile de se la procurer ; des émissions en langue oudmourte sont diffusées, mais elles sont peu nombreuses et, pour la plupart, de qualité médiocre (variétés) ${ }^{6}$.

La poésie de Viktor Šibanov ${ }^{7}$ et, plus récemment, des groupes musicaux comme Tyloburdo ${ }^{8}$ ou Silent Woo Gore ${ }^{9}$, les réalisations en feutre et les dessins d'Anastasija Fertikova $^{10}$, les collections de mode néofolk ${ }^{11}$, tout comme les événements (fêtes ou colloques) du groupe MUSH ${ }^{12}$ constituent les moyens d'expression culturelle des Oudmourtes d'aujourd'hui. Ils sont nettement moins célèbres (aucun concert, défilé ou exposition n'ont réuni un public de plus de 30000 personnes), et souvent considérés comme destinés à une élite intellectuelle et artistique oudmourte.

Uzy Bory s'inscrit dans la continuité de cette culture originale, mais réussit à en dépasser les limites : c'est une offre culturelle facile d'accès qui répond à une demande du grand public. Le film réunit les consommateurs de loisirs visuels quelle que soit leur nationalité tout autant que les Oudmourtes attachés à la persistance de leur culture. Sur le marché du cinéma de ce début de xxI ${ }^{\mathrm{e}}$ siècle, Uzy Bory est un produit culturel concurrentiel qui peut sans vergogne entrer en compétition avec les comédies romantiques russes ${ }^{13} \mathrm{ou}$, plus largement, occidentales. C'est une manifestation culturelle originale qui sort de la confidentialité pour aller vers le grand public, au même titre que les ensembles folkloriques jusqu'à présent, à ceci près que, contrairement à la culture officielle figée dans le passé, ce long métrage interroge l'identité des Oudmourtes dans leur situation actuelle (la construction d'une culture citadine et d'une identité composite).

Avec Uzy Bory, la culture oudmourte tient sa place et se montre de taille à utiliser les codes et moyens d'expression d'aujourd'hui pour témoigner de ce qu'elle est. Ce film, 
dans la lignée des initiatives culturelles originales citées précédemment, constitue le symbole de l'avènement d'une culture oudmourte contemporaine non plus confidentielle, mais concurrentielle; c'est une position stratégique que nous espérons voir se consolider avec le prochain film de Piotr Pałgan qui devrait traiter

des possibilités de lutter contre l'assimilation des jeunes oudmourtes à Iževsk, de préserver leur langue, leur culture et leur esprit dans un environnement russe [...] où il faut se battre pour l'argent, pour trouver un emploi, pour avoir une situation sociale, et où ils n'ont pas beaucoup de temps pour réfléchir à ce qu'est leur identité nationale. ${ }^{14}$

La sortie de ce film soulève une autre question dans le champ de réflexion de la construction identitaire des minorités finno-ougriennes de Russie: comment interpréter la participation d'acteurs non-nationaux au développement de la culture nationale? En effet, l'instigateur d'Uzy Bory n'est pas oudmourte, ni même finnoougrien, mais il vit à Iževsk; de même, le compositeur du premier opéra national komi $\left(\right.$ Kuratov, 2009) ${ }^{15}$, quoique né à Syktyvkar, vient de Londres. Ce mouvement d'inclusion des « étrangers sympathisants » dans une identité collective oudmourte, ou komie, ne favoriserait-il pas l'intégration de la culture minoritaire dans une culture mondiale, susceptible de la soutenir ? Et réciproquement, ne permettrait-il pas aux peuples finnoougriens de Russie de s'affranchir d'une représentation d'eux-mêmes construite par distinction et exclusion de l'autre, le Russe?

\section{NOTES}

1. Pour voir le film sous-titré en français par S. Cagnoli :

http://www.youtube.com/watch?v=Vu_LW_2RBIs

2. Antoni SŁONIMSKI (1895-1976) était poète, auteur dramatique et journaliste. Cofondateur, entre les deux guerres, du groupe poétique "Skamander» et collaborateur de "Wiadomości Literackie » («Les Nouvelles littéraires»), il a passé la guerre en France et en Grande-Bretagne. Après son retour au pays, il fut président de l'Union des Écrivains polonais (1956-1959), et instigateur de nombreuses résolutions de l'opposition, notamment de la «Lettre des 34 ». Symbole et autorité de l'intelligentsia libérale, il a été, à la fin de sa vie, l'un des initiateurs de son rapprochement avec l'Église.

Source :

http://tygodnik.onet.pl/ 35,0,56938,les_polonais_au_secours_des_juifs_1939-1944__rcits__souvenirs_ddocuments,artykul.html

3. Vojtek Kanevski pour le montage.

4. En russe : СОЮЗ КОМИТЕТОВ СОЛДАТСКИХ МАТЕРЕЙ РОССИИ.

5. Entretien du 20 janvier 2012.

6. Le nouveau programme (2010-2014) est principalement à destination des enfants (ouvrages, manuels, émissions de télé). 
7. Poète oudmourte ethnofuturiste.

8. On peut écouter l'utilisation des instruments oudmourtes traditionnels par ce groupe exclusivement féminin à cette adresse :

http://www.myspace.com/tyloburdo

9. On peut l'écouter à cette adresse :

http://www.myspace.com/silentwoogoore

10. Artiste issue de famille mixte (oudmourte et russe), A. Fertikova réalise des œuvres artisanales et artistiques où des savoir-faire et des matériaux traditionnels oudmourtes cohabitent avec des thèmes d'inspiration mixte. Pour voir ses travaux :

http://vk.com/id10952900

11. Les collections de mode néofolk présentent des vêtements d'inspiration oudmourte (coloris, formes, textiles, tissage ou broderie) adaptés à la vie moderne et citadine.

12. Les objectifs du groupe MUSH sont notamment la modernisation des ressources culturelles finno-ougriennes (création d'un réseau social, d'une terminologie et de programmes informatiques pour l'oudmourte), la construction de représentations de l'avenir pour les peuples finno-ougriens (conférences, cours de langue gratuits à Moscou, republication de livres finno-ougriens rares, y compris ceux des années 1920 et 1930).

13. D'après moi, Uzy Bory est néanmoins nettement moins kitsch que les comédies romantiques russes, qui sont imbattables en la matière.

14. Entretien du 20 janvier 2012.

15. Pour en savoir plus :

www.adefo.org/doc/2009.11.19-presentation.ppt;

Cagnoli Sébastien, Fantapié Henti-Claude, "Kuratov de Serge Noskov. Ecrire un opéra national au XXI siècle », EFO n42, 2010, p. 127-158.

INDEX

Thèmes : cinéma

Mots-clés : cinéma oudmourte, culture grand public, sauvegarde culturelle

Index chronologique : XXIe siècle, XXIe siècle (début)

nomsmotscles Oudmourtes, Russes

Index géographique : Budapest, France, Iževsk, Royaume-Uni, Oudmourtie (République)

disciplines français, oudmourte, polonais, russe

Keywords : Cultural preservation, main stream culture, udmurt film, twenty-first century

(beginning), French, Russian, Polish, Udmurt, Russians, Budapest, France, Izhevsk, Udmurtia, United Kingdom 